\title{
FACTORS ASSOCIATED WITH SEXUAL RISK BEHAVIOUR AMONG YOUNG PEOPLE IN UKRAINE
}

\author{
Romana Pylypchuk, Cicely Marston \\ Department of Public Health and Policy, London School of Hygiene and Tropical Medicine, London, UK
}

\begin{abstract}
SUMMARY
We used data from a behavioural survey of Ukrainian men and women aged 14-24 to examine the relationship between nine potential risk factors and two HIV risk outcomes: non-use of condom at last sex, and multiple sexual partnerships. Younger age at first sex was positively associated with both health risk outcomes, and condom non-use at first sex was associated with subsequent non-use of condoms at last sex. There were regional differences in frequencies of both HIV risk behaviours. Compared with those who reported living in the place they were born, not living permanently at the current place of residence was associated with a fivefold increase in the odds of multiple partnership for women but not for men. Alcohol and drug use were associated with higher odds of multiple partnership and the effect was greater among women than among men. The data analysed are cross-sectional so cannot establish causality. More studies are needed to confirm these results and investigate causal relationships between the possible risk factors and the two health risk behaviours.
\end{abstract}

Key words: HIV, sexual risk behaviour, young men, young women, survey, Ukraine

Address for correspondence: Romana Pylypchuk, Department of Public Health and Policy, London School of Hygiene and Tropical Medicine, 50 Bedford Square, London WC1B3DP, UK, E-mail: romana_pylypchuk@yahoo.co.uk

\section{INTRODUCTION}

The STI (Sexually Transmitted Infections) increase which took place in the countries of Eastern Europe after the collapse of the Soviet Union was particularly pronounced among young people and indicates high prevalence of sexual risk behaviours in this group (1).

Currently the number of new HIV infections in Ukraine is the second highest in the WHO European Region (2). In 2006, the 18-24 yearolds constituted $17,6 \%$ of the new HIV cases in Ukraine (3).

The HIV epidemic in Ukraine started among populations such as injecting drug users. Transmission through non-sexual means (e.g. sharing contaminated needles) is still the most important mode of infection $(3,4)$. However, the role of heterosexual transmission has increased in the last decade: proportionally fewer affected individuals have any direct relationship with drug users (3). From 1997 to 2006, the proportion of HIV transmission attributed to injecting drug use decreased from $83,6 \%$ to $44,3 \%$, and the proportion of heterosexual transmission increased from $11,3 \%$ to $35,3 \%$ (3).

In the first six months of 2007, most new HIV infections in Ukraine occurred either through non-sexual blood transmission routes, primarily injecting drug use $(41,8 \%)$, or through unprotected sexual contact $(37,4 \%)$ (4). From 1998 to the present day, most HIV infection through heterosexual transmission has occurred among 20- to 39- year-old men and women, with increasingly higher proportions of cases among women than men (4).

In Ukraine, there are important inter-regional differences in incidence of HIV, which is the highest in the east and south of the country and in the city of Kiev, and lowest in the west. These differences have been attributed to the different prevalence of injecting drug use in those regions (3).

There has been a limited research on young people's sexual behavior in the countries of the former Soviet Union. However, this is a group with distinctive characteristics compared with adults with regard to health risk behaviour, which need to be taken into account for targeted interventions (5).

Research outside the former Soviet Union has identified a number of factors associated with high risk sexual behaviour among young people. Early sexual debut has been associated with lower odds of using contraceptives and increased odds of multiple sexual partners $(6,7)$. Condom use at first sexual intercourse has been associated with subsequent condom use $(8,9)$. Large age differences between partners at first sex has been associated with less safe sexual behaviour (10-12).

Greater religiosity has been reported to be associated with less sexual activity and proportionally less condom use when sexual activity does occur (13).

There is no clear correlation between reported perceived HIV risk and reported risk behaviour. In some cases, perceived susceptibility to HIV is a significant predictor of higher condom use (14), but in others, perceiving the risk of becoming infected as high or medium does not correspond with higher condom use (15). In one study, young men reporting high risk behaviours also perceived themselves (probably accurately) at risk of HIV (16).

Migration has been identified as an independent risk factor for the acquisition of $\operatorname{HIV}(17,18)$. Use of alcohol and drugs are associated with increased sexual risk behaviour and infection with STIs and HIV (19-22). 
The purpose of this study was to examine factors associated with risky sexual behaviour among Ukrainian young people aged 14-24. We examine the effects of several exposure variables found to be associated with sexual risk behaviour in other settings on two outcomes representing sexual risk behaviour: condom nonuse at last sex and having three and more sexual partners within the last year. The proportion of sexually active young people who report using a condom for their most recent sexual intercourse is used as an estimate of sexual risk behaviour in other studies (23). Recall of behaviour such as condom use, is acknowledged to be less challenging to respondents when linked to a specific event and may be less prone to social desirability bias $(24,25)$. Also, use of condom at most recent sexual intercourse appears to be a reasonable proxy for consistent use, as the two measures have been found to be highly correlated both in cross sectional and prospective studies $(26,27)$.

\section{METHODS}

\section{Study Population}

This analysis is based on the sample of young people from the survey 'Monitoring of Youth Behaviour as a Component of SecondGeneration Epidemiological Surveillance' conducted by the State Institute of Family and Youth Problems and the Ukrainian Institute for Social Research, with the support of AIDS Alliance Ukraine. The survey was carried out between October 22 and November 13, 2004, in all the regions of Ukraine, AR Crimea, and the city of Kiev among young people 14 to 24 years old. The survey used a multistage stratified random sampling approach to ensure that the sample represents the general population by main socio-demographic characteristics (sex, age, type of the place of residence, region). Overall, 95\% of the identified young men and women were interviewed.

The survey method was a structured face-to-face interview. A combined interview approach was used. This consisted of a face-to-face individual interview collecting general information, and a confidential self-administered questionnaires containing sensitive questions. After the face-to-face interview, the respondents filled in the self-administered questionnaire, sealed it in a separate envelope and returned it to the interviewer.

The survey collected information from young people about their sexual behaviour, sources of condoms, pregnancy history, knowledge of and attitudes to HIV/AIDS. Demographic data were also collected.

\section{Measures}

Sexual risk behaviour among those who reported being sexually active during the last 12 months in this study is based on two indicators: multiple sexual partners during the last year, and condom non-use at last sex.

Multiple partnership is defined as having three or more sexual partners in the last 12 months.

Because of the way the questionnaire was worded, for the purpose of analysis it was necessary to combine variables indicating condom use at most recent vaginal sex and most recent anal sex. If a person reported using condom at both vaginal and anal sex, or either kind of sex (when reporting just one of them), they are considered 'lower risk'; if a person reported not using condom at either vaginal or anal sex or both, they are considered 'higher risk'.
Respondent characteristics/exposure variables include current age, sex and marital status of respondent, age at first sex, age difference from partner at first sex, condom use at first sex (the survey did not distinguish between anal and vaginal sex in questions about "first sex"), religiosity, perceived risk of HIV, migration status, current region of residence, alcohol and drug use.

We used $\chi^{2}$ tests to assess univariate associations between the dichotomous outcome variables and the exposure variables. Logistic regression was used to calculate the odds ratios for both outcomes, adjusted for the explanatory variables described above. In the logistic regression models, current age was fitted as continuous variable, while age at first sex, age difference from partner at first sex, alcohol use, and perceived risk of HIV were treated as ordered categorical variables. Interaction between each exposure variable and demographic variables (current age, sex, marital status) were assessed with likelihood ratio tests. For significant interactions, we conducted logistic regression stratifying by the exposure variable that showed a significant correlation. Because sex interacted with marital status, we analyzed men and women separately.

\section{RESULTS}

The distribution of responses by exposure and outcome variables is presented in Tables 1 and 2.

\section{Condom Non-use at Last Sex - Univariate Results}

Forty-nine percent of respondents (539 individuals) reported non-use of condoms at last sex. Table 3 shows the crude odds ratios for non-use of condom among women and men, and each exposure variable.

Men and women who reported not using condom at first sex were significantly more likely to report unprotected intercourse at last sexual encounter: OR 4.39 (95\% CI 3.07, 6.27) for men and OR 4.01 (95\% CI 2.74, 5.88) for women. Compared with women who estimate their HIV risk as high, women who believe they are not at risk of contracting HIV were more likely to report non-use of condoms, OR 1.76 (95\% CI 1.11, 2.78). Region of residence was significantly related to condom non-use among men who live in the north and east [respective odds ratios 2.12 (95\% CI 1.18, 3.8) and 2.53 (95\% CI 1.55, 4.13)], compared with men who live in the west. There was no such relationship among women.

Age at first sex, age difference between partners at first sex, religiosity, recent migration, reported alcohol and drug use were not significantly related to likelihood of condom use at last intercourse for men or women.

\section{Multivariate Results}

Marital status, sex, and current age were significantly associated with non-use of condoms. Married and cohabiting respondents were more likely to report condom non-use, and proportionally more women than men reported not using condoms at most recent intercourse. Increasing age was related to decreasing condom use at last sex.

Table 4 shows the odds ratios for non-use of condom among women and men adjusted for marital status and current age.

Older age at first sex seems to have a protective effect in that it is associated with higher odds of condom use at last sexual in- 
Table 1. Distribution of the responses of the Ukrainian men and women aged 14-24 who had sex in the last year, on the selected exposure variables, by multiple sexual partnership

\begin{tabular}{|c|c|c|c|c|c|c|c|}
\hline \multicolumn{8}{|c|}{ Whether or not the respondent reported multiple partnership } \\
\hline \multirow[b]{2}{*}{ Variable } & \multicolumn{2}{|c|}{$\begin{array}{l}\text { Reported multiple } \\
\text { partnership }\end{array}$} & \multirow[t]{2}{*}{ Row total } & \multirow[b]{2}{*}{ Variable } & \multicolumn{2}{|c|}{$\begin{array}{l}\text { Reported multiple } \\
\text { partnership }\end{array}$} & \multirow[t]{2}{*}{ Row total } \\
\hline & $\mathrm{N}$ & $\%$ (row) & & & $\mathrm{N}$ & $\%$ (row) & \\
\hline Marital status & & & & Condom use at first sex & & & \\
\hline Not married/divorced/widowed & 301 & 33.78 & 891 & Yes & 166 & 25.38 & 654 \\
\hline Married/cohabiting & 39 & 9.42 & 414 & No & 157 & 27.07 & 580 \\
\hline Total & 340 & 26.05 & 1305 & Total & 323 & 26.18 & 1234 \\
\hline \multicolumn{4}{|l|}{ Pearson $X^{2}(1)=87.0778 P \leq 0.001$} & \multicolumn{4}{|c|}{ Pearson $X^{2}(1)=0.4526 P=0.501$} \\
\hline Current age & & & & Religiosity & & & \\
\hline $14-16$ & 26 & 27.96 & 93 & Believers & 161 & 23.03 & 699 \\
\hline $17-19$ & 97 & 27.25 & 356 & Doubting & 96 & 26.89 & 357 \\
\hline $20+$ & 217 & 25.29 & 858 & Non-believers/atheists & 73 & 34.60 & 211 \\
\hline Total & 340 & 26.01 & 1307 & Total & 330 & 26.05 & 1267 \\
\hline \multicolumn{4}{|l|}{ Pearson $X^{2}(2)=0.6965 P=0.706$} & \multicolumn{4}{|c|}{ Pearson $X^{2}(2)=11.4368 P=0.003$} \\
\hline Sex & & & & Age at first sex & & & \\
\hline Female & 81 & 13.39 & 605 & $10-16$ & 178 & 34.50 & 516 \\
\hline Male & 259 & 36.89 & 702 & $17-19+$ & 135 & 19.68 & 686 \\
\hline Total & 340 & 26.01 & 1307 & Total & 313 & 26.04 & 1202 \\
\hline \multicolumn{4}{|l|}{ Pearson $X^{2}(1)=93.2880 P \leq 0.001$} & \multicolumn{4}{|c|}{ Pearson $X^{2}(1)=33.5693 P \leq 0.001$} \\
\hline Estimated HIV risk & & & & $\begin{array}{l}\text { Migration status } \\
\text { Born and live here }\end{array}$ & 260 & 25.62 & 1015 \\
\hline Absolutely real/quite real & 103 & 36.27 & 284 & Do not live permanently & 26 & 40.00 & 65 \\
\hline $50-50$ & 86 & 36.13 & 238 & $1-5$ years & 30 & 25.64 & 117 \\
\hline Unlikely/not at risk absolutely & 127 & 18.51 & 686 & $6-16+$ & 24 & 21.82 & 110 \\
\hline Total & 316 & 26.16 & 1208 & Total & 340 & 26.01 & 1307 \\
\hline \multicolumn{4}{|l|}{ Pearson $X^{2}(2)=48.0465 P \leq 0.001$} & \multicolumn{4}{|c|}{ Pearson $X^{2}(3)=7.7044 P=0.053$} \\
\hline & & & & Region of residence & & & \\
\hline & & & & West & 62 & 23.66 & 262 \\
\hline Age difference with the partner at first sex & & & & Centre & 34 & 20.12 & 169 \\
\hline Older & 166 & 22.83 & 727 & North & 62 & 33.33 & 186 \\
\hline Same age & 78 & 27.56 & 283 & East & 91 & 24.14 & 377 \\
\hline Younger & 56 & 31.82 & 176 & South & 44 & 27.85 & 158 \\
\hline \multirow[t]{3}{*}{ Total } & 300 & 25.30 & 1186 & Crimea & 15 & 23.44 & 64 \\
\hline & & & & Kiev & 32 & 35.16 & 91 \\
\hline & & & & Total & 340 & 26.01 & 1307 \\
\hline \multicolumn{4}{|l|}{ Pearson $X^{2}(2)=7.0637 P=0.029$} & \multicolumn{4}{|c|}{ Pearson $X^{2}(6)=14.1266 P=0.028$} \\
\hline Drug use & & & & $\begin{array}{l}\text { Alcohol use last month } \\
\text { At least once a week }\end{array}$ & 172 & 44.91 & 383 \\
\hline No & 278 & 23.13 & 1202 & Less that once a week & 143 & 21.83 & 655 \\
\hline Yes & 54 & 61.36 & 88 & Never used & 20 & 8.47 & 236 \\
\hline Total & 332 & 25.74 & 1290 & Total & 335 & 26.30 & 1274 \\
\hline \multicolumn{4}{|l|}{ Pearson $X^{2}(1)=62.7202 P \leq 0.001$} & \multicolumn{4}{|c|}{ Pearson $X^{2}(2)=113.8699 P \leq 0.001$} \\
\hline
\end{tabular}

tercourse. Men who were over 17 years old at sexual debut were less likely to report non-use of condom at last sex compared with the baseline category of those who were 10-16 years old at their first sex (OR 0.67 (95\% CI 0.45, 0.97).
Young women and men who reported not using condoms at their first sexual intercourse were nearly four times more likely to report non use of condom at last sex compared with those who reported using condom at sexual debut. Young men who lived in 
Table 2. Distribution of the responses of the Ukrainian men and women aged 14-24 who had sex in the last year, on the selected exposure variables, by non-use of condom at last sex

\begin{tabular}{|c|c|c|c|c|c|c|c|}
\hline \multicolumn{8}{|c|}{ Whether or not the respondent reported non-use of condom at last sex } \\
\hline \multirow[b]{2}{*}{ Variable } & \multicolumn{2}{|c|}{$\begin{array}{l}\text { Reported condom } \\
\text { non-use }\end{array}$} & \multirow[t]{2}{*}{ Row total } & \multirow[b]{2}{*}{ Variable } & \multicolumn{2}{|c|}{$\begin{array}{l}\text { Reported condom } \\
\text { non-use }\end{array}$} & \multirow[t]{2}{*}{ Row total } \\
\hline & $\mathrm{N}$ & $\%$ (row) & & & $\mathrm{N}$ & $\%$ (row) & \\
\hline Marital status & & & & Condom use at first sex & & & \\
\hline Not married/divorced/widowed & 282 & 36.67 & 769 & Yes & 175 & 32.29 & 542 \\
\hline Married/cohabiting & 256 & 76.42 & 335 & No & 340 & 67.06 & 507 \\
\hline Total & 538 & 48.73 & 1104 & Total & 515 & 49.09 & 1049 \\
\hline \multicolumn{4}{|l|}{ Pearson $X^{2}(1)=147.5531 P \leq 0.001$} & \multicolumn{4}{|c|}{ Pearson $X^{2}(1)=126.7438 P \leq 0.001$} \\
\hline Current age & & & & Religiosity & & & \\
\hline $14-16$ & 27 & 32.93 & 82 & Believers & 283 & 49.13 & 576 \\
\hline $17-19$ & 122 & 40.13 & 304 & Doubting & 153 & 49.84 & 307 \\
\hline $20+$ & 390 & 54.17 & 720 & Non-believers/atheists & 90 & 46.39 & 194 \\
\hline Total & 539 & 48.73 & 1106 & Total & 526 & 48.84 & 1077 \\
\hline \multicolumn{4}{|l|}{ Pearson $X^{2}(2)=25.7107 P \leq 0.001$} & \multicolumn{4}{|c|}{ Pearson $X^{2}(2)=0.6072 P=0.738$} \\
\hline Sex & & & & Age at first sex & & & \\
\hline Female & 288 & 56.69 & 508 & $10-16$ & 225 & 50.11 & 449 \\
\hline Male & 251 & 41.97 & 598 & $17-19+$ & 276 & 48.59 & 568 \\
\hline Total & 539 & 48.73 & 1106 & Total & 501 & 49.26 & 1017 \\
\hline \multicolumn{4}{|l|}{ Pearson $X^{2}(1)=23.8201 P \leq 0.001$} & \multicolumn{4}{|c|}{ Pearson $X^{2}(1)=0.2317 P=0.630$} \\
\hline Estimated HIV risk & & & & $\begin{array}{l}\text { Migration status } \\
\text { Born and live here }\end{array}$ & 422 & 48.62 & 868 \\
\hline Absolutely real/quite real & 115 & 45.63 & 252 & Do not live permanently & 25 & 46.30 & 54 \\
\hline $50-50$ & 89 & 44.95 & 198 & $1-5$ years & 50 & 53.76 & 93 \\
\hline Unlikely/Not at risk absolutely & 292 & 51.32 & 569 & $6-16+$ & 42 & 46.15 & 91 \\
\hline Total & 496 & 48.68 & 1019 & Total & 539 & 48.73 & 1106 \\
\hline \multicolumn{4}{|l|}{ Pearson $X^{2}(2)=3.6234 P=0.163$} & \multicolumn{4}{|c|}{ Pearson $X^{2}(3)=1.3172 P=0.725$} \\
\hline & & & & Region of residence & & & \\
\hline & & & & West & 92 & 41.26 & 223 \\
\hline Age difference with the partner at first sex & & & & Centre & 77 & 55.40 & 139 \\
\hline Older & 317 & 52.05 & 609 & North & 65 & 48.51 & 134 \\
\hline Same age & 95 & 39.09 & 243 & East & 172 & 54.09 & 318 \\
\hline Younger & 70 & 47.30 & 148 & South & 62 & 41.06 & 151 \\
\hline \multirow[t]{3}{*}{ Total } & 482 & 48.20 & 1000 & Crimea & 33 & 55.93 & 59 \\
\hline & & & & Kiev & 38 & 46.34 & 82 \\
\hline & & & & Total & 539 & 48.73 & 1106 \\
\hline \multicolumn{4}{|l|}{ Pearson $X^{2}(2)=11.7376 P=0.003$} & \multicolumn{4}{|c|}{ Pearson $X^{2}(6)=16.0833 P=0.013$} \\
\hline Drug use & & & & $\begin{array}{l}\text { Alcohol use last month } \\
\text { At least once a week }\end{array}$ & 141 & 41.96 & 336 \\
\hline No & 493 & 48.76 & 1011 & Less that once a week & 275 & 50.09 & 549 \\
\hline Yes & 42 & 53.16 & 79 & Never used & 107 & 56.91 & 188 \\
\hline Total & 535 & 49.08 & 1090 & Total & 523 & 48.74 & 1073 \\
\hline \multicolumn{4}{|l|}{ Pearson $X^{2}(1)=0.5679 P=0.451$} & \multicolumn{4}{|c|}{ Pearson $X^{2}(2)=11.6041 P=0.003$} \\
\hline
\end{tabular}

the east and north were over twice as likely to report non-use of condoms compared with those who live in the western regions (OR 2.58 (95\% CI 1.52, 4.37) and OR 2.39 (95\% CI 1.28, 4.45) respectively).
Women who assessed their HIV risk as 'unlikely' or 'no risk at all' were 1.9 times more likely to report not using a condom at most recent intercourse, after taking account of the effect of marital status and current age. 
Table 3. Likelihood of reporting non-use of condom at last sex, for 14-24 years old Ukrainian women and men, unadjusted odds ratios $(O R)$ using logistic regression analysis

\begin{tabular}{|c|c|c|c|c|c|c|}
\hline \multirow[t]{2}{*}{ Exposure variable } & Crude OR & $95 \% \mathrm{Cl}$ & $\mathrm{p}$ & Crude OR & $95 \% \mathrm{Cl}$ & $p$ \\
\hline & \multicolumn{3}{|c|}{ Women } & \multicolumn{3}{|c|}{ Men } \\
\hline Age at first sex & & & & & & \\
\hline $10-16$ & 1 & & & 1 & & \\
\hline $17+$ & 0.80 & $0.53,1.20$ & 0.265 & 0.80 & $0.57,1.13$ & 0.208 \\
\hline Age difference with partner at first sex & & & & & & \\
\hline Partner $5+$ years older & 1 & & & 1 & & \\
\hline Partner 1-4 years older & 0.99 & $0.65,1.50$ & 0.945 & 0.81 & $0.40,1.62$ & 0.545 \\
\hline Same age & 0.78 & $0.44,1.41$ & 0.414 & 0.64 & $0.32,1.28$ & 0.206 \\
\hline Partner 1-4 years younger & 1.25 & $0.35,4.48$ & 0.729 & 1.04 & $0.51,2.11$ & 0.912 \\
\hline Condom use at first sex & & & & & & \\
\hline Yes & 1 & & & 1 & & \\
\hline No & 4.01 & $2.74,5.88$ & $<0.001$ & 4.39 & $3.07,6.27$ & $<0.001$ \\
\hline Religiosity & & & & & & \\
\hline Believer & 1 & & & 1 & & \\
\hline Doubt & 1.19 & $0.79,1.79$ & 0.397 & 0.97 & $0.65,1.43$ & 0.869 \\
\hline Non-believer & 1.22 & $0.67,2.21$ & 0.517 & 0.97 & $0.64,1.46$ & 0.879 \\
\hline Estimated HIV risk & & & & & & \\
\hline Absolutely real/quite real & 1 & & & 1 & & \\
\hline $50-50$ & 1.28 & $0.71,2.32$ & 0.413 & 0.80 & $0.49,1.29$ & 0.364 \\
\hline Unlikely/not at risk at all & 1.76 & $1.11,2.78$ & 0.015 & 0.90 & $0.6,1.33$ & 0.587 \\
\hline Recent migration & & & & & & \\
\hline Born and live here & 1 & & & 1 & & \\
\hline Do not live permanently & 0.91 & $0.32,2.57$ & 0.863 & 1.04 & $0.54,2.02$ & 0.90 \\
\hline Less than a year/1-5 years & 1.43 & $0.79,2.59$ & 0.239 & 0.90 & $0.47,1.74$ & 0.754 \\
\hline $6-16+$ years & 1.17 & $0.59,2.33$ & 0.65 & 0.79 & $0.44,1.42$ & 0.438 \\
\hline Region of residence & & & & & & \\
\hline West & 1 & & & 1 & & \\
\hline Centre & 1.84 & $0.94,3.61$ & 0.074 & 1.76 & $0.97,3.18$ & 0.062 \\
\hline North & 0.74 & $0.38,1.44$ & 0.375 & 2.12 & $1.18,3.8$ & 0.011 \\
\hline East & 1.00 & $0.60,1.67$ & 0.988 & 2.53 & $1.55,4.13$ & $<0.001$ \\
\hline South & 0.84 & $0.46,1.54$ & 0.575 & 1.04 & $0.56,1.9$ & 0.908 \\
\hline AR Crimea & 2.65 & $0.98,7.20$ & 0.055 & 1.49 & $0.67,3.30$ & 0.327 \\
\hline Kiev & 0.80 & $0.38,1.69$ & 0.552 & 1.74 & $0.86,3.53$ & 0.125 \\
\hline Drug use & & & & & & \\
\hline No & 1 & & & 1 & & \\
\hline Yes & 1.2 & $0.46,3.16$ & 0.706 & 1.46 & $0.86,2.48$ & 0.166 \\
\hline Alcohol use in past month & & & & & & \\
\hline At least once a week & 1 & & & 1 & & \\
\hline Less than once a week & 1.02 & $0.61,1.71$ & 0.929 & 1.24 & $0.88,1.76$ & 0.222 \\
\hline Never used & 1.25 & $0.71,2.23$ & 0.441 & 1.44 & $0.8,2.59$ & 0.219 \\
\hline
\end{tabular}

\section{Multiple Sexual Partners - Univariate Results}

Twenty-six percent of the respondents (340 individuals) reported having three or more sexual partners within last 12 months. Table 5 presents the crude odds ratios for multiple sexual partnership among men and women.
In the univariate analysis, older age at first sex was significantly related to reduced odds of having three or more sexual partners in the last year. Women whose first sexual partner was 1-4 years older were less likely to have multiple partners compared with women whose first partner was 5 or more years older, OR 0.48 
(95\% CI 0.28, 0.83). Compared with those who estimate their HIV risk as real, women and men who believe they are not at risk of HIV were less likely to report multiple partnerships (OR $=0.39(95 \%$ CI $0.22,0.7)$ and $\mathrm{OR}=0.45$ [(95\% CI 0.31, 0.66), respectively]. Women living in Kiev were over three times as likely to report multiple partnerships as women in the west. Women and men who reported using drugs were also more likely to report multiple partnerships [OR=9.03 (95\% CI 3.61, 22.58) and $\mathrm{OR}=3.39$ (95\% CI 2.02, 5.70) respectively].

Condom use at first sex, religiosity, recent migration, and alcohol use in the past month were not significantly related to multiple partnership in the univariate analysis.

\section{Multivariate Results}

Marital status and sex, but not current age, were significantly associated with reports of multiple sexual partnerships in the multivariate analysis. Unsurprisingly, never-married people were more likely to report multiple partners in the last year compared with married and cohabiting respondents. Among unmarried, non-cohabiting respondents who were sexually active in the last year, $66 \%$ reported having one or two partners, and 34\% reported having three or more. More men than women said they had three or more sexual partners.

Table 6 presents the adjusted odds ratios for multiple partnership in women and men.

Respondents who were 17 years and older at sexual onset were less likely to report having three or more partners during the last year, compared with those who were 16 or younger at first sex [adjusted OR 0.59 (95\% CI 0.35, 0.99) for women; adjusted OR 0.45 (95\% CI 0.32, 0.64) for men]. Reporting a partner at first sex who is 1-4 years older, of same age, or younger, was associated with reduced odds of multiple partnership, compared with individuals whose partner was substantially (five or more years) older.

Women who report condom non-use at first sex are over twice as likely to report multiple partnerships than women who report having used condoms at first sex.

Estimating one's HIV risk as 'unlikely' or 'no risk at all' was associated with lower likelihood of reporting multiple partnership by women [OR 0.39 (95\% CI 0.21, 0.71)] and men [adjusted OR 0.47 (95\% CI 0.32, 0.70)].

Women who reported not living permanently in their current place of residence were over five times more likely to report multiple sexual partners compared with women who reported living in the town or city where they were born. There was no such relationship for their male counterparts.

Odds of multiple partnership were higher for women residing in Kiev [adjusted OR 2.78 (95\% CI 1.04, 7.4)], compared with women living in the west of the country. Region of residence was not significantly related to multiple partnership for men.

Drug use was significantly associated with reports of multiple partnership among both among men and women, with the effect much stronger in women [OR 8.97 (95\% CI 3.38, 23.76)] for women compared with OR 3.57 (95\% CI 2.08, 6.13) for men.

Drinking less alcohol was associated with reduced odds of reporting multiple sexual partnership for both men and women, with the strongest effect among women who reported using no alcohol during the last month.

\section{DISCUSSION}

The purpose of this study was to investigate relationships between nine potential risk factors and sexual risk behaviour among young people aged 14-24 in Ukraine. The results suggest that most of the exposure variables are associated with either multiple sexual partnership or condom non-use. Some of the variables are associated with both risk outcomes.

Significant positive relationships for men and women were found between condom non-use at first sex and non-use of condoms at last sex. Younger age at first sex was also positively associated with both multiple partnership and condom non-use.

Women who report that their own risk of HIV is very low were almost twice as likely as women who consider themselves at high risk to report non-use of condoms after taking account of marital status and current age. These women may therefore be more likely to assume they are not at risk despite having unprotected sex, perhaps because they perceive their sexual partner as safe or for other reasons. This may put some of them at risk if the partner is not monogamous or is infected with HIV.

Among both men and women, perception of low HIV risk was associated with reduced likelihood of reporting multiple partnership and could be the consequence of less risky behaviour.

Alcohol non use was associated with significantly reduced likelihood of reports of multiple sexual partnership among both men and women, with the protective effect most prominent among women who never drink alcohol. However, frequency of alcohol use was not related to condom use at last sex. This is consistent with previous research findings of the positive link between drinking and indiscriminate behaviours such as having multiple sex partners, and the inconsistent link between alcohol use or non-use and protective behaviours such as condom use (28-31).

The relationship between the region of residence and reported condom non-use was significant only for men living in the eastern and northern regions but it suggests possible regional differences in risk behaviour, or at least of reporting that behaviour, as does the significant positive relationship between residing in the city of Kiev and multiple sexual partnerships among women. The city of Kiev and the east and north regions belong to the group of regions most affected by the HIV epidemic, and respondents from these regions are more likely to report non-use of condoms and multiple partnerships compared with respondents from the west region where HIV prevalence is lower. This suggests that the east and north regions as well as Kiev should be a priority area for interventions to tackle sexual risk behaviour.

A significantly older partner, as well as younger age at first sexual intercourse is associated with increased odds of reporting multiple sexual partnerships, even after accounting for the influence of other demographic variables. This finding chimes with studies in other settings which indicate that having a much older partner is associated with subsequent sexual risk bevaviour $(10,11)$.

The association between migration status and multiple partnerships was only significant for women who reported they did not live permanently in the current place of residence. It is possible that being in a temporary location might give women opportunities for sexual activity otherwise restricted by family members or others, but this would need to be investigated by future research.

In common with other studies (31-33), reported drug use is signifi- 
Table 4. Likelihood of reporting non-use of condom at last sex, for 14-24 years old Ukrainian women and men, adjusted odds ratios (OR) using logistic regression analysis

\begin{tabular}{|c|c|c|c|c|c|c|}
\hline Exposure variable & Adjusted OR & $95 \% \mathrm{Cl}$ & $\mathrm{p}$ & Adjusted OR & $95 \% \mathrm{Cl}$ & $\mathrm{p}$ \\
\hline & \multicolumn{3}{|c|}{ Women } & \multicolumn{3}{|c|}{ Men } \\
\hline Age at first sex & & & & & & \\
\hline $10-16$ & 1 & & & 1 & & \\
\hline $17+$ & 0.74 & $0.48,1.12$ & 0.158 & 0.67 & $0.45,0.97$ & 0.036 \\
\hline Age difference with partner at first sex & & & & & & \\
\hline Partner 5+ years older & 1 & & & 1 & & \\
\hline Partner 1-4 years older & 0.89 & $0.57,1.39$ & 0.608 & 0.86 & $0.41,1.81$ & 0.70 \\
\hline Same age & 0.72 & $0.38,1.34$ & 0.299 & 0.57 & $0.27,1.21$ & 0.145 \\
\hline Partner 1-4 years younger & 1.37 & $0.36,5.28$ & 0.647 & 1.01 & $0.47,2.15$ & 0.983 \\
\hline Condom use at first sex & & & & & & \\
\hline Yes & 1 & & & 1 & & \\
\hline No & 3.74 & $2.49,5.60$ & $<0.001$ & 3.95 & $2.71,5.73$ & $<0.001$ \\
\hline Religiosity & & & & & & \\
\hline Believer & & & & & & \\
\hline Doubt & 1.14 & $0.74,1.76$ & 0.544 & 0.95 & $0.62,1.46$ & 0.818 \\
\hline Non-believer & 1.32 & $0.70,2.48$ & 0.396 & 1.14 & $0.73,1.77$ & 0.569 \\
\hline Estimated HIV risk & & & & & & \\
\hline Absolutely real/quite real & 1 & & & 1 & & \\
\hline $50-50$ & 1.56 & $0.82,2.97$ & 0.172 & 0.78 & $0.46,1.3$ & 0.346 \\
\hline Unlikely/not at risk at all & 1.90 & $1.16,3.12$ & 0.011 & 0.77 & $0.5,1.18$ & 0.23 \\
\hline Recent migration & & & & & & \\
\hline Born and live here & 1 & & & 1 & & \\
\hline Do not live permanently & 1.02 & $0.35,3.02$ & 0.97 & 0.89 & $0.43,1.82$ & 0.742 \\
\hline Less than a year/1-5 years & 1.27 & $0.67,2.40$ & 0.467 & 0.57 & $0.27,1.21$ & 0.142 \\
\hline $6-16+$ years & 1.16 & $0.56,2.41$ & 0.685 & 0.76 & $0.41,1.41$ & 0.380 \\
\hline Region of residence & & & & & & \\
\hline West & 1 & & & 1 & & \\
\hline Centre & 1.49 & $0.73,3.03$ & 0.274 & 1.73 & $0.91,3.27$ & 0.093 \\
\hline North & 0.88 & $0.43,1.78$ & 0.721 & 2.39 & $1.28,4.45$ & 0.006 \\
\hline East & 1.16 & $0.67,1.99$ & 0.593 & 2.58 & $1.52,4.37$ & $<0.001$ \\
\hline South & 0.98 & $0.52,1.88$ & 0.959 & 1.15 & $0.68,1.69$ & 0.683 \\
\hline AR Crimea & 2.59 & $0.9,7.41$ & 0.076 & 1.58 & $0.68,3.69$ & 0.292 \\
\hline Kiev & 1.06 & $0.48,2.34$ & 0.891 & 1.96 & $0.93,4.15$ & 0.079 \\
\hline Drug use & & & & & & \\
\hline No & 1 & & & 1 & & \\
\hline Yes & 1.47 & $0.53,4.08$ & 0.456 & 1.55 & $0.88,2.72$ & 0.126 \\
\hline Alcohol use in past month & & & & & & \\
\hline At least once a week & 1 & & & 1 & & \\
\hline Less than once a week & 0.72 & $0.41,1.24$ & 0.233 & 1.16 & $0.8,1.68$ & 0.432 \\
\hline Never used & 0.73 & $0.39,1.36$ & 0.322 & 1.02 & $0.53,1.96$ & 0.948 \\
\hline
\end{tabular}

cantly associated with risk -in this case, a higher likelihood of reporting multiple sexual partnership, with a much stronger effect in women.

This study has several limitations. We rely on young people's reports of their behaviour, which may not be accurate, although the self-administered questionnaire format may have reduced social desirability bias. Type of partner (permanent, casual, commercial) of the reported last vaginal and anal sex is not specified. We suspect this would have been illuminating. Frequency of alcohol use was assessed only for the past month; therefore we do not know the frequency of alcohol intake which occurred outside this 
Table 5. Likelihood of reporting three or more sexual partners during the last year, for 14-24 years old Ukrainian women and men, unadjusted odds ratios (OR) using logistic regression analysis

\begin{tabular}{|c|c|c|c|c|c|c|}
\hline Exposure variable & Crude OR & $95 \% \mathrm{Cl}$ & $\mathrm{p}$ & Crude OR & $95 \% \mathrm{Cl}$ & $\mathrm{p}$ \\
\hline & \multicolumn{3}{|c|}{ Women } & \multicolumn{3}{|c|}{ Men } \\
\hline Age at first sex & & & & & & \\
\hline $10-16$ & 1 & & & 1 & & \\
\hline $17+$ & 0.52 & $0.32,0.85$ & 0.009 & 0.52 & $0.38,0.73$ & $<0.001$ \\
\hline Age difference with partner at first sex & & & & & & \\
\hline Partner 5+ years older & 1 & & & 1 & & \\
\hline Partner 1-4 years older & 0.48 & $0.28,0.83$ & 0.009 & 0.85 & $0.44,1.64$ & 0.634 \\
\hline Same age & 0.58 & $0.26,1.29$ & 0.18 & 0.62 & $0.32,1.2$ & 0.153 \\
\hline Partner 1-4 years younger & 0.41 & $0.05,3.29$ & 0.4 & 0.61 & $0.31,1.19$ & 0.146 \\
\hline Condom use at first sex & & & & & & \\
\hline Yes & 1 & & & 1 & & \\
\hline No & 1.61 & $0.98,2.65$ & 0.058 & 1.10 & $0.8,1.51$ & 0.564 \\
\hline Religiosity & & & & & & \\
\hline Believer & 1 & & & 1 & & \\
\hline Doubt & 1.00 & $0.58,1.74$ & 0.989 & 1.23 & $0.85,1.78$ & 0.267 \\
\hline Non-believer & 1.46 & $0.71,3.01$ & 0.299 & 1.37 & $0.92,2.04$ & 0.121 \\
\hline Estimated HIV risk & & & & & & \\
\hline Absolutely real/quite real & 1 & & & 1 & & \\
\hline $50-50$ & 1.12 & $0.57,2.18$ & 0.75 & 0.96 & $0.61,1.49$ & 0.84 \\
\hline Unlikely/not at risk at all & 0.39 & $0.22,0.7$ & 0.002 & 0.45 & $0.31,0.66$ & $<0.001$ \\
\hline Recent migration & & & & & & \\
\hline Born and live here & 1 & & & 1 & & \\
\hline Do not live permanently & 5.78 & $2.39,13.95$ & $<0.001$ & 0.99 & $0.53,1.9$ & 0.99 \\
\hline Less than a year/1-5 years & 0.87 & $0.38,1.99$ & 0.736 & 1.25 & $0.71,2.20$ & 0.44 \\
\hline $6-16+$ years & 0.69 & $0.24,2.01$ & 0.499 & 0.73 & $0.42,1.27$ & 0.27 \\
\hline Region of residence & & & & & & \\
\hline West & 1 & & & 1 & & \\
\hline Centre & 0.87 & $0.3,2.49$ & 0.791 & 0.81 & $0.46,1.42$ & 0.465 \\
\hline North & 2.36 & $1.0,5.57$ & 0.049 & 1.51 & $0.90,2.52$ & 0.118 \\
\hline East & 2.08 & $0.98,4.42$ & 0.057 & 0.84 & $0.53,1.32$ & 0.443 \\
\hline South & 1.21 & $0.45,3.21$ & 0.708 & 1.46 & $0.84,2.54$ & 0.179 \\
\hline AR Crimea & 0.39 & $0.05,3.14$ & 0.373 & 1.16 & $0.55,2.46$ & 0.694 \\
\hline Kiev & 3.36 & $1.28,8.8$ & 0.014 & 1.44 & $0.75,2.76$ & 0.278 \\
\hline Drug use & & & & & & \\
\hline No & 1 & & & 1 & & \\
\hline Yes & 9.03 & $3.61,22.58$ & $<0.001$ & 3.39 & $2.02,5.70$ & $<0.001$ \\
\hline Alcohol use in past month & & & & & & \\
\hline At least once a week & 1 & & & 1 & & \\
\hline Less than once a week & 0.35 & $0.21,0.61$ & $<0.001$ & 0.45 & $0.32,0.63$ & $<0.001$ \\
\hline Never used & 0.05 & $0.02,0.16$ & $<0.001$ & 0.31 & $0.17,0.56$ & $<0.001$ \\
\hline
\end{tabular}

period. Also, we have very little information about the frequency or type of drugs used by the respondents.

Another limitation is that the data analyzed in our study are cross-sectional, therefore causal relationships can not be established. Finally, as with any survey, there may be factors that contributed to the two health risk behaviours which have not been examined in this study. 
Table 6. Likelihood of reporting three or more sexual partners during the last year, for 14-24 years old Ukrainian women, adjusted odds ratios (OR) using logistic regression analysis

\begin{tabular}{|c|c|c|c|c|c|c|}
\hline Exposure variable & Adjusted OR & $95 \% \mathrm{Cl}$ & $\mathrm{p}$ & Adjusted OR & $95 \% \mathrm{Cl}$ & $p$ \\
\hline & \multicolumn{3}{|c|}{ Women } & \multicolumn{3}{|c|}{ Men } \\
\hline Age at first sex & & & & & & \\
\hline $10-16$ & 1 & & & 1 & & \\
\hline $17+$ & 0.59 & $0.35,0.99$ & 0.049 & 0.45 & $0.32,0.64$ & $<0.001$ \\
\hline Age difference with partner at first sex & & & & & & \\
\hline Partner $5+$ years older & 1 & & & 1 & & \\
\hline Partner 1-4 years older & 0.45 & $0.26,0.80$ & 0.006 & 0.78 & $0.38,0.88$ & 0.467 \\
\hline Same age & 0.55 & $0.24,1.26$ & 0.16 & 0.57 & $0.3,0.78$ & 0.113 \\
\hline Partner 1-4 years younger & 0.34 & $0.04,2.81$ & 0.32 & 0.55 & $0.26,0.76$ & 0.1 \\
\hline Condom use at first sex & & & & & & \\
\hline Yes & 1 & & & 1 & & \\
\hline No & 2.01 & $1.21,3.36$ & 0.007 & 1.30 & $0.93,1.81$ & 0.122 \\
\hline Religiosity & & & & & & \\
\hline Believer & 1 & & & 1 & & \\
\hline Doubt & 1.05 & $0.59,1.84$ & 0.87 & 1.30 & $0.89,1.9$ & 0.175 \\
\hline Non-believer & 1.5 & $0.72,3.15$ & 0.28 & 1.35 & $0.9,2.03$ & 0.145 \\
\hline Estimated HIV risk & & & & & & \\
\hline Absolutely real/quite real & 1 & & & 1 & & \\
\hline $50-50$ & 0.99 & $0.5,1.98$ & 0.99 & 0.97 & $0.62,1.53$ & 0.90 \\
\hline Unlikely/not at risk at all & 0.39 & $0.21,0.71$ & 0.002 & 0.47 & $0.32,0.70$ & $<0.001$ \\
\hline Recent migration & & & & & & \\
\hline Born and live here & 1 & & & 1 & & \\
\hline Do not live permanently & 5.35 & $2.14,13.38$ & $<0.001$ & 1.11 & $0.57,2.18$ & 0.75 \\
\hline Less than a year/1- 5 years & 0.97 & $0.41,2.27$ & 0.95 & 1.58 & $0.86,2.87$ & 0.14 \\
\hline $6-16+$ years & 0.70 & $0.24,2.06$ & 0.52 & 0.75 & $0.43,1.33$ & 0.33 \\
\hline Region of residence & & & & & & \\
\hline West & 1 & & & 1 & & \\
\hline Centre & 1.14 & $0.39,3.34$ & 0.816 & 0.89 & $0.50,1.59$ & 0.699 \\
\hline North & 2.2 & $0.92,5.28$ & 0.077 & 1.52 & $0.9,2.58$ & 0.117 \\
\hline East & 1.93 & $0.89,4.16$ & 0.096 & 0.90 & $0.57,1.44$ & 0.674 \\
\hline South & 1.1 & $0.41,2.97$ & 0.854 & 1.42 & $0.8,2.49$ & 0.229 \\
\hline AR Crimea & 0.41 & $0.05,3.39$ & 0.406 & 1.20 & $0.56,2.59$ & 0.643 \\
\hline Kiev & 2.78 & $1.04,7.4$ & 0.041 & 1.37 & $0.70,2.68$ & 0.352 \\
\hline Drug use & & & & & & \\
\hline No & 1 & & & 1 & & \\
\hline Yes & 8.97 & $3.38,23.76$ & $<0.001$ & 3.57 & $2.08,6.13$ & $<0.001$ \\
\hline Alcohol use in past month & & & & & & \\
\hline At least once a week & 1 & & & 1 & & \\
\hline Less than once a week & 0.43 & $0.25,0.77$ & 0.004 & 0.47 & $0.33,0.66$ & $<0.001$ \\
\hline Never used & 0.07 & $0.02,0.21$ & $<0.001$ & 0.36 & $0.19,0.67$ & 0.001 \\
\hline
\end{tabular}

\section{REFERENCES}

1. Kelly JA, Amirkhanian YA. The newest epidemic: a review of HIV/AIDS in Central and Eastern Europe. Int J STD AIDS. 2003Jun;14(6):361-71.

2. Euro HIV. HIV/AIDS Surveillance in Europe. End-year report 2005. No73. Saint-Maurice: Sanitary Surveillance Institute; 2006.
3. Sakalska OP, Scherbinska AM, Bochkova LV, Schkurko TV, Gural AL, Kruglov YV, et al. HIV Infection in Ukraine. Information Bulletin. No. 27. Kyiv: Ministry of Health of Ukraine; 2007. (In Ukrainian.)

4. Scherbinska AM, Bochkova LV, Gural AL, Kruglov YV, Martsynovska VA, Nguien IV, et al. HIV Infection in Ukraine. Information Bulletin. No. 28. Kyiv: Ministry of Health of Ukraine; 2007. (In Ukrainian.)

5. Roberts S T, Kennedy BL. Why are young college women not using condoms? Their perceived risk, drug use, and developmental vulnerability 
may provide important clues to sexual risk. Arch Psychiatr Nurs. 2006 Feb;20(1):32-40.

6. Kirby D, Lepore G, Ryan J. Sexual risk and protective factors: factors affecting teen sexual behaviour, pregnancy, childbearing, and sexually transmitted disease - which are important? Which can you change? Washington, D.C.: The National Campaign to Prevent Teen Pregnancy; 2005.

7. Harrison A, Cleland J, Gouws E, Frohlich J. Early sexual debut among young men in rural South Africa: heightened vulnerability to sexual risk? Sex Transm Infect. 2005 Jun;81(3):259-61.

8. Teixeira AM, Knauth DR, Fachel JM, Leal AF. Teenagers and condom use: choices by young Brazilians from three Brazilian State capitals in their first and last sexual intercourse. Cad Saude Publica. 2006 Jul;22(7):138596. Erratum in: Cad Saude Publica. 2006 Sep;22(9):2003-4. (In Portuguese.)

9. Miller KS, Levin ML, Whitaker DJ, Xu X. Patterns of condom use among adolescents: the impact of mother-adolescent communication. Am J Public Health. 1998 Oct;88(10):1542-4.

10. Ford K, Sohn W, Lepkowski J. Characteristics of adolescents‘ sexual partners and their association with use of condoms and other contraceptive methods. Fam Plann Perspect. 2001 May-Jun;33(3):100-5, 132.

11. Di Clemente RJ, Wingood GM, Crosby RA, Sionean C, Cobb BK, Harrington $\mathrm{K}$, et al. Sexual risk behaviours associated with having older sex partners: a study of black adolescent females. Sex Transm Dis. 2002Jan;29(1):20-4.

12. Leitenberg $H$, Saltzman $H$. A statewide survey of age at first intercourse for adolescent females and age of their male partners: relation to other risk behaviours and statutory rape implications. Arch Sex Behav. 2000 Jun;29(3):203-15.

13. Zaleski EH, Schiaffino KM. Religiosity and sexual risk-taking behaviour during the transition to college. J Adolesc. 2000 Apr;23(2):223-7.

14. Adih WK, Alexander CS. Determinants of condom use to prevent HIV infection among youth in Ghana. J Adolesc Health. 1999 Jan;24(1):63-72.

15. Bensyl D, Iuliano D, Colley Gilbert B. Perceived HIV risk and condom use in the behavioral risk factor surveillance system (BRFSS). Ann Epidemiol. 2000 Sep;13(8):594-5.

16. Reitman D, St Lawrence JS, Jefferson KW, Alleyne E, Brasfield TL, Shirley A. Predictors of African American adolescents' condom use and HIV risk behaviour. AIDS Educ Prev. 1996 Dec;8(6):499-515.

17. Lagarde E, Schim van der Loeff M, Enel C, Holmgren B, Dray-Spira R, Pison G, et al; MECORA Group. Mobility and the spread of human immunodeficiency virus into rural areas of West Africa. Int J Epidemiol. 2003 Oct;32(5):744-52.

18. Zuma K, Gouws E, Williams B, Lurie M. Risk factors for HIV infection among women in Carletonville, South Africa: migration, demography and sexually transmitted diseases. Int J STD AIDS. 2003 Dec;14(12):814-7.

19. Koniak-Griffin D, Brecht ML. Linkages between sexual risk taking, substanse use, and AIDS knowledge among pregnant adolescents and young mothers. Nurs Res. 1995 Nov-Dec;44(6):340-6.

20. LaBrie J, Earleywine M, Schiffman J, Pedersen E, Marriot C. Effects of alcohol, expectancies, and partner type on condom use in college males: event-level analyses. J Sex Res. 2005 Aug;42(3):259-66.

21. Baskin-Sommers A, Sommers I. The co-occurrence of substance use and high-risk behaviours. J Adolesc Health. 2006 May;38(5):609-11.

22. Cooper ML. Alcohol use and risky sexual behaviour among college students and youth: evaluating the evidence. J Stud Alcohol Suppl. 2002 Mar;(14):101-17.

23. Wellings K, Collumbien M, Slaymaker E, Singh S, Hodges Z, Patel D, et al. Sexual behaviour in context: a global perspective. Lancet. 2006 Nov 11;368(9548):1706-28.

24. Reitmeijer CA, Lansky A, Anderson JE, Fichtner RR. Developing standards in behavioural surveillance of HIV/STD prevention. AIDS Educ Prev. 2001 Jun;13(3):268-78.

25. Catania JA, Dolcini MM, Laumann EO, Osmond D, Bolan G, Canchola $\mathrm{J}$. A response to „developing standards in behavioural surveillance for HIV/STD prevention“. AIDS Educ Prev. 2002 Aug;14(4):343-7.

26. Lagarde E, Auvert B, Chege J, Sukwa T, Glynn JR, Weiss HA, et al; Study Group on the Heterogeneity of HIV Epidemics in African Cities. Condom use and its association with HIV/sexually transmitted diseases in four urban communities of sub-Saharan Africa. AIDS. 2001 Aug;15 Suppl 4:S71-8.

27. Myer L, Mathews C, Little F. Measuring consistent condom use: a comparison of cross-sectional and prospective measurements in South Africa. Int J STD AIDS. 2002 Jan;13(1):62-3.

28. Santelli JS, Brener ND, Lowry R, Bhatt A, Zabin LS. Multiple sexual partners among U.S. adolescents and young adults. Fam Plann Perspect. 1998 Nov-Dec;30(6):271-5.

29. Wechsler H, Dowdall GW, Davenport A, Castillo S. Correlates of college student binge drinking. Am J Public Health. 1995 Jul;85(7):921-6.

30. Wechsler H, Davenport A, Dowdall G, Moeykens B, Castillo S. Health and behavioral consequences of binge drinking in college: A national survey of students at 140 campuses. JAMA. 1994 Dec 7;272(21):1672-7.

31. Lowry R, Holtzman D, Truman BI, Kann L, Collins JL, Kolbe LJ. Substance use and HIV-related sexual behaviors among US high school students: are they related? Am J Public Health. 1994 Jul;84(7):1116-20.

32. Tapert SF, Aarons GA, Sedlar GR, Brown SA. Adolescent substance use and sexual risk-taking behavior. J Adolesc Health. 2001 Mar;28(3):181-9.

33. Staton M, Leukefeld C, Logan TK, Zimmerman R, Lynam D, Milich R, et al. Risky sex behavior and substance use among young adults. Health Soc Work. 1999 May;24(2):147-54.

Received December 17, 2007 Accepted July 29, 2008 